\title{
SISTEM SELEKSI RELAWAN TENAGA PENGAJAR MENGGUNAKAN METODE TOPSIS
}

\author{
Haris Triono Sigit ${ }^{1}$, Tio Rieka Okta Friyansyah ${ }^{2}$ \\ 1,2 Jurusan Informatika Fakultas Teknologi Informasi Universitas Serang Raya \\ Jln. Raya Cilegon Serang - Drangong Kota Serang \\ ${ }^{1}$ haris.t.sigit@gmail.com \\ 2tio.rieka@gmail.com
}

\begin{abstract}
Abstrak - Setiap organisasi melakukan proses seleksi untuk memperoleh sumber daya manusia yang diharapkan. Demikian pula pada proses rekrutmen relawan tenaga pengajar di Yayasan Istana Belajar Anak Banten (ISBANBAN), proses seleksi dilakukan dengan mempertimbangkan beberapa kriteria, yaitu : Kesiapan Mengabdi Selama 1 tahun, Leadership, Pendekatan terhadap anak dan Karakter Pribadi. Pada proses recruitment yang sedang berjalan, bagian Open Recruitment masih menggunakan penghitungan dengan cara konvensional sehingga hasil penilaian menjadi tidak objektif. Agar mendapatkan hasil penilaian yang objektif maka perlu dilakukan penghitungan dengan menggunakan salah satu metode Sistem Penunjang Keputusan. Pada penelitian ini metode yang digunakan untuk seleksi calon relawan tenaga pengajar adalah metode Technique For Order Preference By Similarity To Ideal Solution (TOPSIS). Metode ini mampu melakukan penilaian yang objektif dan menghasilkan suatu rekomendasi yang dapat digunakan oleh bagian Open Recruitment untuk memutuskan calon relawan tenaga pengajar yang layak dan sesuai dengan kriteria yang diharapkan.
\end{abstract}

Kata kunci - Yayasan Isbanban, Seleksi, Relawan Tenaga Pengajar, Sistem Penunjang Keputusan, TOPSIS.

\section{PENDAHULUAN}

Yayasan Istana Belajar Anak Banten (ISBANBAN) adalah salah satu organisasi yang bergerak di bidang pendidikan. Yayasan ini merupakan yayasan sosial nirbala (non-profit) yang dimotori oleh pemuda atau pemudi yang didirikan pada tanggal 10 Februari 2013. Pendirian yayasan ini adalah untuk membantu anak-anak dari keluarga miskin di daerah pedesaan Banten untuk mencapai akses pendidikan yang unggul. Tiga tujuan utama gerakan ISBANBAN Foundation adalah : meningkatkan akses pendidikan anak, meningkatkan literasi minat baca anak dan meningkatkan angka partisipasi sekolah anak di sekolah di pelosok desa Banten.

Salah satu kegiatan yang dijalankan oleh yayasan ISBANBAN adalah program Minggu Belajar, yaitu Program pengajaran yang dilakukan setiap hari minggu oleh para relawan pengajar kepada adik-adik di desa binaan. Program ini dikhususkan untuk membantu terdorongnya wawasan anak di pelosok desa Banten. Dalam menjalankan program kerjanya, yayasan ISBANBAN memerlukan sejumlah relawan pengajar untuk ditempatkan di desa-desa binaan yang tersebar di wilayah Cilegon, Kabupaten Serang, Kabupaten Tangerang, Kota Serang, Lebak, Pandeglang dan Tangerang Selatan.

Proses mendapatkan relawan pengajar yang dilakukan oleh yayasan ISBANBAN adalah dengan mengadakan Open Recruitment untuk menjaring calon relawan. Selanjutnya dilakukan seleksi wawancara calon relawan guna mendapatkan relawan yang berkualitas dan memiliki komitmen yang tinggi untuk mengabdi. Proses penilaian dari hasil wawancara terhadap calon relawan saat ini dilakukan hanya dengan menggunakan cara penghitungan biasa atau standar yaitu dengan menghitung nilai rata-rata dari sejumlah kriteria penilaian sehingga hasil penilaian menjadi kurang objektif dan kurang tepat sasaran.

Berdasarkan latar belakang pemikiran diatas, maka perlu dilakukan penelitian mengenai perekrutan relawan pada bagian Open Recruitment relawan tenaga pengajar di Yayasan ISBANBAN dengan memanfaatkan metode pada Sistem Penunjang Keputusan, dimana pada penelitian ini metode yang akan digunakan adalah metode Technique For Order Preference By Similarity To Ideal Solution (TOPSIS). 


\section{Metodologi Penelitian}

Pada penelitian ini tahapan yang dilakukan diawali dengan mengumpulkan data secara langsung, tepat, akurat dan sesuai dengan kejadian yang sebenarnya.

\section{Metode Pengumpulan Data}

Metode pengumpulan data adalah cara pengumpulan data untuk keperluan dalam pelaksaaan penelitian. metode pengumpulan data dalam penelitian ini dengan alur kegiatan sebagai berikut :

a. Studi Lapangan

Yaitu pengumpulan data yang dilakukan langsung di Yayasan Istana Belajar Anak Banten (ISBANBAN) dengan cara sebagai berikut:

1) Wawancara, mengajukan pertanyaan secara langsung kepada bagian rekrutmen calon relawan pengajar.

2) Observasi, melakukan pengamatan langsung serta melihat proses perekrutan calon relawan untuk mendapatkan gambaran yang jelas mengenai objek penelitian

b. Studi Kepustakaan

Yaitu pencarian data yang diperlukan dari sumbersumber informasi seperti buku-buku, artikel, jurnal dan dengan mempelajari literaturyang tersedia di lapangan mengenai data yang diperlukan untuk penelitian ini.

\section{Analisa Sistem}

Pada tahap ini akan dilakukan analisis terhadap permasalahan yang ada serta menemukan solusi yang tepat bagi penyelesaian masalah tentang proses perekrutan calon relawan.

3. Perancangan Sistem

Berdasarkan hasil analisa, maka dilakukan perancangan dengan menggunakan Unified Modelling Language. Selanjutnya dilakukan desain basis data, user interface dan struktur program aplikasi recruitment calon relawan pengajar.

\section{Pembuatan Program}

Pembuatan program ini berdasarkan kegiatan pembuatan aplikasi berdasarkan perancangan sistem yang telah dibuat dengan menggunakan XAMPP yang kemudian diproses dan dilakukan editing hingga menghasilkan sebuah sistem informasi berbasis web yang diinginkan. Program dibuat dengan menggunakan MySQL sebagai databasenya dan PHP sebagai bahasa pemrogramannya.

\section{Testing}

Pada tahap ini dilakukan pengujian aplikasi untuk menghindari kesalahan yang mungkin terjadi serta kelemahan program, sehingga apabila ditemukan kelemahan atau kekurangan bisa segera diperbaiki. Metode yang digunakan untuk pengujian adalahBlackbox Testing.

\section{Implementasi Sistem}

Implementasi sistem adalah tahapan akhir dimana aplikasi yang sudah dibuat akan diterapkan atau dioperasikan pada Yayasan Istana Belajar Anak Banten (ISBANBAN).

\section{HASIL DAN PEMBAHASAN}

Berdasarkan hasil pengamatan dan wawancara yang telah dilakukan di Yayasan Istana Belajar Anak Banten (ISBANBAN) proses perekrutan calon relawan masih menggunakan penghitungan dengan cara biasa. Hal ini akan mengakibatkan kurang objektif dan akuratnya penilaian terhadap calon relawan pengajar. Guna mengatasi tersebut maka perlu diterapkan suatu Sistem Pendukung Keputusan, guna mempermudah dan mempersingkat waktu dan juga demi keakuratan hasil yang lebih maksimal dan lebih baik.

\section{A. Gambaran Umum Objek Penelitian}

Pada yayasan ISBANBAN ini, proses dalam perekrutan relawan pengajar adalah sebagai berikut:

1. Bagian perekrutan membuka lowongan untuk penerimaan relawan tenaga pengajar yang akan ditempatkan di desa binaan.

2. Setelah mendapatkan calon relawan maka dilakukan wawancara untuk mengetahui potensi yang dimiliki oleh calon relawan.

3. Berdasarkan hasil wawancara dilakukan penilaian untuk mengetahui calon relawan pengajar yang dapat diterima untuk menjadi relawan pengajar di Yayasan Istana Belajar Anak Banten (ISBANBAN).

Guna menyelesaikan permasalahan pada proses perekrutan relawan pengajar pada Yayasan Istana Belajar Anak Banten (ISBANBAN), dibangunlah suatu sistem pendukung keputusan untuk mempermudah dalam penentuan calon relawan yang layak untuk diterima menjadi relawan pengajar sesuai dengan penghitungan dari masing-masing kriteria.

Dalam proses perekrutan ini digunakan metode TOPSIS (Technique For Order Reference by Similarity to Ideal Solution). TOPSIS menggunakan prinsip bahwa alternatif yang terpilih harus mempunyai jarak terdekat dari solusi ideal positif dan terjauh dari solusi ideal negatif dari sudut pandang geometris dengan menggunakan jarak Euclidean untuk menentukan kedekatan relatif dari suatu alternatif dengan solusi optimal.

\section{B. Penghitungan Metode TOPSIS}

\section{Alternatif}

Dalam penelitian ini dipakai data sampel lima calon relawan 
Tabel 1. Alternatif

\begin{tabular}{|c|l|}
\hline Kode & \multicolumn{1}{|c|}{ Alternatif } \\
\hline A1 & Ahmad Maulana Aliudin \\
\hline A2 & Ari Apriyanti \\
\hline A3 & Asep Awaludin \\
\hline A4 & Aulia Octaviani Priyatna \\
\hline A5 & Demi Mutia Putaru \\
\hline
\end{tabular}

2. Kriteria

Adapun atribut atau kriteria yang dipakai pada penelitianini yaitu:

Tabel 2. Kriteria

\begin{tabular}{|c|l|}
\hline Kode & \multicolumn{1}{|c|}{ Kriteria } \\
\hline C1 & Kesiapan Mengabdi Selama 1 tahun \\
\hline C2 & Leadership \\
\hline C3 & Pendekatan terhadap anak \\
\hline C4 & Karakter Pribadi \\
\hline
\end{tabular}

3. Memberikan Rating Kecocokan

Proses ini menjelaskan nilai-nilai yang digunakan untuk menentukan nilai preferensi sebagai nilai perbandingan tiap-tiap kriteria, antara lain adalah sebagai berikut.

a. Kesiapan Mengabdi Selama 1 tahun.

Kriteria ini diberikan bobot maksimal 4 dengan ketentuan:

$\begin{array}{ll}\text { Kurang } & : 1 \\ \text { Cukup } & : 2 \\ \text { Baik } & : 3 \\ \text { Sangat Baik } & : 4\end{array}$

b. Kriteria Leadership

Kriteria Leadershipdiberikan bobot maksimal 4 dengan ketentuan:

$\begin{array}{ll}\text { Kurang } & : 1 \\ \text { Cukup } & : 2 \\ \text { Baik } & : 3 \\ \text { Sangat Baik } & : 4\end{array}$

c. Kriteria Pendekatan terhadap anak

Kriteria ini diberikan bobot maksimal 4 dengan ketentuan:

$\begin{array}{ll}\text { Kurang } & : 1 \\ \text { Cukup } & : 2 \\ \text { Baik } & : 3 \\ \text { Sangat Baik } & : 4\end{array}$

d. Kriteria Karakter Pribadi

Kriteria ini diberikan bobot maksimal 4 dengan ketentuan:

$\begin{array}{ll}\text { Kurang } & : 1 \\ \text { Cukup } & : 2 \\ \text { Baik } & : 3 \\ \text { Sangat Baik } & : 4\end{array}$

\section{Pembobotan Keputusan}

Dalam menentukan suatu keputusan diterima atau tidaknya menjadi relawan pengajar mengacu pada alternatif yang mendominasi alternatif lainnya atau sebagai alternatif yang memiliki rangking paling tinggi dibandingkan dengan alternatif lainnya.

Dengan demikian perlu ditetapkan pula bobot preferensi dari tiap kriteria sebagai tingkat kepentingan antara ke empat kriteria. Dalam penelitian ini bobot penilaian yang ditentukan oleh bagian recruitment relawan pengajar adalah sebagai berikut:

Tabel 3. Kriteria dengan Preferensi Bobot

\begin{tabular}{|c|l|c|}
\hline Kode & \multicolumn{1}{|c|}{ Kriteria } & Preferensi \\
\hline C1 & $\begin{array}{l}\text { Kesiapan Mengabdi Selama 1 } \\
\text { tahun }\end{array}$ & 0.4 \\
\hline C2 & Leadership & 0.15 \\
\hline C3 & Pendekatan terhadap anak & 0.15 \\
\hline C4 & Karakter Pribadi & 0.3 \\
\hline
\end{tabular}

\section{Perhitungan Data Dengan Metode TOPSIS}

TOPSIS membutuhkan rating kinerja setiap alternatif Ai yang ternormalisasi pada setiap kriteria $\mathrm{Cj}$ yaitu:

$$
\mathrm{r}_{\mathrm{ij}}=\frac{\mathrm{x}_{\mathrm{ij}}}{\sqrt{\sum_{\mathrm{i}=1}^{\mathrm{m}} \mathrm{x}_{\mathrm{ij}}^{2}}}
$$

Solusi ideal positif $\mathrm{A}^{+}$dan dan solusi ideal negatif $\mathrm{A}^{-}$ dapat ditentukan berdasarkan rating bobot ternormalisasi $\left(\mathrm{y}^{\mathrm{ij}}\right)$ sebagai berikut

$$
\begin{aligned}
& \mathrm{y}_{\mathrm{ij}}=\mathrm{w}_{\mathrm{i}} \mathbf{r}_{\mathrm{ij}} \\
& \mathrm{A}^{+}=\left(\mathrm{y}_{1}^{+}, \mathrm{y}_{2}^{+}, \cdots, \mathrm{y}_{\mathrm{n}}^{+}\right) ; \\
& \mathrm{A}^{-}=\left(\mathrm{y}_{1}^{-}, \mathrm{y}_{2}^{-}, \cdots, \mathrm{y}_{\mathrm{n}}^{-}\right),
\end{aligned}
$$

Jarak antara alternatif Ai dengan solusi ideal positif dirumuskan sebagai

$$
\mathrm{D}_{\mathrm{i}}^{+}=\sqrt{\sum_{\mathrm{j}=1}^{\mathrm{n}}\left(\mathrm{y}_{\mathrm{i}}^{+}-\mathrm{y}_{\mathrm{ij}}\right)^{2}} \text {; }
$$

Nilai preferensi untuk setiap alternatif $\mathrm{Vi}$ diberikan sebagai berikut 


$$
\mathrm{V}_{\mathrm{i}}=\frac{\mathrm{D}_{\mathrm{i}}^{-}}{\mathrm{D}_{\mathrm{i}}^{-}+\mathrm{D}_{\mathrm{i}}^{+}}
$$

Urutan langkah-langkah pemecahan masalah dalam penelitian dalam penelitian ini adalah sebagai berikut: Menentukan lima alternative calon relawan dengan contoh:

Tabel 4. Tabel Alternatif.

\begin{tabular}{|c|l|}
\hline Kode & \multicolumn{1}{|c|}{ Alternatif } \\
\hline A1 & Ahmad Maulana Aliudin \\
\hline A2 & Ari Apriyanti \\
\hline A3 & Asep Awaludin \\
\hline A4 & Aulia Octaviani Priyatna \\
\hline A5 & Demi Mutia Putaru \\
\hline
\end{tabular}

Kriteria yang digunakan sebagai berikut : Table 4. Tabel Kriteria

\begin{tabular}{|c|l|}
\hline Kode & \multicolumn{1}{|c|}{ Kriteria } \\
\hline C1 & Kesiapan Mengabdi Selama 1 tahun \\
\hline C2 & Leadership \\
\hline C3 & Pendekatan terhadap anak \\
\hline C4 & Karakter Pribadi \\
\hline
\end{tabular}

Rating kecocokan setiap alternatif pada kriteria adalah sebagai berikut:

Tabel 5. Tabel Penilaian Alternatif per Kriteria

\begin{tabular}{|c|c|c|c|c|}
\hline \multirow{2}{*}{ Alternatif } & \multicolumn{5}{|c|}{ Kriteria } \\
\cline { 2 - 5 } & $\mathrm{C} 1$ & $\mathrm{C} 2$ & $\mathrm{C} 3$ & $\mathrm{C} 4$ \\
\hline A1 & 2 & 3 & 4 & 1 \\
\hline A2 & 3 & 3 & 2 & 2 \\
\hline A3 & 1 & 4 & 3 & 2 \\
\hline A4 & 1 & 3 & 2 & 4 \\
\hline A5 & 1 & 2 & 2 & 3 \\
\hline
\end{tabular}

Langkah selanjutnya yang harus dilakukan adalah:

1. Membuat matriks keputusan yang ternormalisasi Untuk menormalisai kita harus mengkuadratkan setiap elemen matriks rating kecocokan alternatif. Tabel 6. Tabel Alternatif pengkuadratan

\begin{tabular}{|c|c|c|c|c|}
\hline \multirow{2}{*}{ Alternatif } & \multicolumn{4}{|c|}{ Kriteria } \\
\cline { 2 - 5 } & $\mathrm{C} 1$ & $\mathrm{C} 2$ & $\mathrm{C} 3$ & $\mathrm{C} 4$ \\
\hline A1 & 2 & 3 & 4 & 1 \\
\hline A2 & 3 & 3 & 2 & 2 \\
\hline A3 & 1 & 4 & 3 & 2 \\
\hline A4 & 1 & 3 & 2 & 4 \\
\hline
\end{tabular}

A5

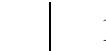

$1 \quad 2$

2

2

3

Menjadi:

Tabel 7. Tabel normalisasi.

\begin{tabular}{|c|c|c|c|c|}
\hline $\begin{array}{c}\text { Alternatif } \\
\text { / Kriteria }\end{array}$ & C1 & C2 & C3 & C4 \\
\hline $\mathbf{A 1}$ & 0.5 & 0.43759 & 0.6576 & 0.171 \\
\hline $\mathbf{A 2}$ & 0.75 & 0.43759 & 0.3288 & 0.343 \\
\hline $\mathbf{A 3}$ & 0.25 & 0.58346 & 0.4932 & 0.343 \\
\hline $\mathbf{A 4}$ & 0.25 & 0.43759 & 0.3288 & 0.686 \\
\hline $\mathbf{A 5}$ & 0.25 & 0.29173 & 0.3288 & 0.514 \\
\hline
\end{tabular}

Cara perhitungan untuk mendapatkan nilai matriks ternormalisasi seperti diatas dengan membagi nilai alternatif dengan nilai total hasil pada table perpangkatan, misalkan

$\mathrm{A} 1-\mathrm{C} 1=2 / \operatorname{sqrt}((2 * 2)+(3 * 3)+(1 * 1)+(1 * 1)+(1 * 1))=0.5$

2. Membuat matriks keputusan yang ternormalisasi terbobot

Untuk menentukan matriks ternormaliasi terbobot, bobot kepentingan dikalikan dengan matriks ternomalisasi. Bobot untuk masing-masing kriteria adalah :

$\mathrm{C} 1=40 \%, \mathrm{C} 2=15 \%, \mathrm{C} 3=15 \%$ dan $\mathrm{C} 4=30 \%$

Tabel 8. Matriks ternormalisasi terbobot

\begin{tabular}{|c|c|c|c|c|}
\hline $\begin{array}{c}\text { Alternatif } \\
\text { / Kriteria }\end{array}$ & C1 & C2 & C3 & C4 \\
\hline $\mathbf{A 1}$ & 0.2 & 0.06564 & 0.0986 & 0.051 \\
\hline $\mathbf{A 2}$ & 0.3 & 0.06564 & 0.0493 & 0.103 \\
\hline $\mathbf{A 3}$ & 0.1 & 0.08752 & 0.074 & 0.103 \\
\hline $\mathbf{A 4}$ & 0.1 & 0.06564 & 0.0493 & 0.206 \\
\hline $\mathbf{A 5}$ & 0.1 & 0.04376 & 0.0493 & 0.154 \\
\hline
\end{tabular}

Cara penyelesaian diambil contoh pada baris A1.

Baris A1 diperoleh dengan:

$(0.2 * 0.4)=0.5,(0.43759 * 0.15)=0.06564$,

$(0.6576 * 0.15)=0.0986,(0.171 * 0.3)=0.051$.

3. Menentukan matriks solusi ideal positif \& matriks solusi ideal negatif 
Untuk menentukan matriks solusi ideal positif dan negative yaitu dengan memasukan fungsi $M A X$ (nilai maksimal)untuk positif dan MIN (nilai minimal) untuk negatif pada masing masing baris table kriteria. Pada matrik terbobot

Tabel 9. Matriks solusi ideal Positif danNegatif.

\begin{tabular}{|c|c|c|c|c|}
\hline & C1 & C2 & C3 & C4 \\
\hline $\mathrm{V}+$ & 0.3 & 0.08752 & 0.0986 & 0.206 \\
\hline $\mathrm{V}-$ & 0.1 & 0.04376 & 0.0493 & 0.051 \\
\hline
\end{tabular}

Contoh penyelesaian untuk mendapatkan nilai pada table matriks solusi ideal positif dan negatif misalnya pada kolom $\mathrm{C} 1$ sebagai berikut :

Positif $\mathrm{C} 1=$ Nilai maximum dari $(0.2,0.3,0.1,0.1,0.1)$ $=0.3$

Negatif C1=Nilai minimum dari $(0.2,0.3,0.1,0.1,0.1)$ $=0.1$

4. Menentukan jarak antara nilai setiap alternatif dengan matriks solusiideal positif \& matriks solusi ideal negatif

Matrix solusi ideal positif

$$
\mathrm{D}_{\mathrm{i}}^{+}=\sqrt{\sum_{\mathrm{j}=1}^{\mathrm{n}}\left(\mathrm{y}_{\mathrm{i}}^{+}-\mathrm{y}_{\mathrm{ij}}\right)^{2}}
$$

Contoh penghitungan solusi ideal positif dan negatif pada baris A1, adalah sebagai berikut :

$$
D_{1}^{+}=\sqrt{\begin{array}{l}
(0.2-0.3)^{2}+ \\
(0.06564-0.08752)^{2}+ \\
(0.0986-0.0986)^{2}+ \\
(0.051-0.206)^{2}
\end{array}}=0.01850
$$

Matrix solusi ideal negatif

$$
\begin{gathered}
D_{i}^{-}=\sqrt{\sum_{j=1}^{n}\left(y_{i j}-y_{i}^{-}\right)^{2}} ; \\
D_{1}^{-}=\sqrt{\begin{array}{l}
(0.2-0.1)^{2}+ \\
(0.06564-0.04376)^{2}+ \\
(0.0986-0.0493)^{2}+ \\
(0.051-0.051)^{2}
\end{array}}=0.114
\end{gathered}
$$

Hasil selengkapnya seperti pada tabel di bawah ini :

Tabel 10. Matrik solusi ideal positif dan negatif

\begin{tabular}{|c|c|c|c|c|}
\hline $\begin{array}{c}\text { Alternatif / } \\
\text { Kriteria }\end{array}$ & $\mathbf{C 1}$ & $\mathbf{C 2}$ & $\mathbf{C 3}$ & $\mathbf{C 4}$ \\
\hline $\mathbf{A 1}$ & 0.2 & 0.06564 & 0.0986 & 0.051 \\
\hline $\mathbf{A 2}$ & 0.3 & 0.06564 & 0.0493 & 0.103 \\
\hline $\mathbf{A 3}$ & 0.1 & 0.08752 & 0.074 & 0.103 \\
\hline $\mathbf{A 4}$ & 0.1 & 0.06564 & 0.0493 & 0.206 \\
\hline $\mathbf{A 5}$ & 0.1 & 0.04376 & 0.0493 & 0.154 \\
\hline
\end{tabular}

\begin{tabular}{|c|c|c|}
\hline $\begin{array}{c}\text { Alternatif / } \\
\text { Kriteria }\end{array}$ & Di+ & Di- \\
\hline $\mathbf{A 1}$ & 0.185 & 0.114 \\
\hline $\mathbf{A 2}$ & 0.116 & 0.208 \\
\hline $\mathbf{A 3}$ & 0.226 & 0.072 \\
\hline $\mathbf{A 4}$ & 0.207 & 0.156 \\
\hline $\mathbf{A 5}$ & 0.217 & 0.103 \\
\hline
\end{tabular}

5. Menentukan nilai preferensi untuk setiap alternatif Untuk mencari nilai total dan perangkingan/ nilai preferensi dengan membagi nilai solusi ideal negatif dengan hasil penjumlah solusi ideal positif dan negatif..

$$
\mathrm{V}_{\mathrm{i}}=\frac{\mathrm{D}_{\mathrm{i}}^{-}}{\mathrm{D}_{\mathrm{i}}^{-}+\mathrm{D}_{\mathrm{i}}^{+}}
$$

Contoh penghitungan pada baris Alternatif A1 adalah sebagai berikut :

$$
V=\frac{0.1}{0.1+0.0}=0.3
$$

Hasil penghitungan selengkapnya seperti terlihat pada tabel di bawah ini :

Tabel 11. Hasil Perangkingan

\begin{tabular}{|c|c|c|c|}
\hline $\begin{array}{c}\text { Alternatif / } \\
\text { Kriteria }\end{array}$ & Si+ & Si- & Pi \\
\hline $\mathbf{A 1}$ & 0.185 & 0.114 & 0.38 \\
\hline
\end{tabular}




\begin{tabular}{|l|l|l|l|}
\cline { 2 - 4 } A2 & 0.116 & 0.208 & 0.641 \\
\hline $\mathbf{A 3}$ & 0.226 & 0.072 & 0.241 \\
\hline $\mathbf{A 4}$ & 0.207 & 0.156 & 0.429 \\
\hline $\mathbf{A 5}$ & 0.217 & 0.103 & 0.322 \\
\hline
\end{tabular}

Setelah menyelesaikan perhitungan berdasarkan data diatas, alternatif yang terbaik dan memiliki preferensi terbesar didapatkan $\mathrm{A} 2$, yaitu dengan nilai preferensi $\mathrm{A} 2=0.641$

\section{KESIMPULAN}

Dari hasil penelitian mengenai Sistem Pendukung Keputusan untuk perekrutan relawan tenaga pengajar dengan menggunakan Metode Technique For Order Reference by Similarity to Ideal Solution (TOPSIS) pada Yayasan Istana Belajar Anak Banten (ISBANBAN), maka dapat disimpulkan:

1. Dengan menggunakan metode TOPSIS, hasil proses rekrutmen menjadi lebih objektif karena penghitungannya dengan mempertimbangkan aspek penilaian dari setiap kriteria.

2. Berdasarkan hasil penilaian yang objektif ini, PIHAK Yayasan dapat dengan mudah melakukan pemilihan relawan tenaga pengajar yang ideal untuk ditempatkan di desa-desa binaan.

\section{REFERENSI}

[1] Website Yayasan Istana Belajar Anak Banten. [Online]. (2019) Tersedia : https://isbanban.org/about.

[2] Sparague, R. H. and Watson H. J. (1993). Decision Support Systems: Putting Theory Into Practice. Englewood Clifts, N. J., Prentice Hall.

[3] Turban , Efraim \& Aronson, Jay E. (2001). Decision Support Systems and Intelligent Systems. 6th edition. Prentice Hall: Upper Saddle River, NJ.

[4] Kusumadewi, Sri; Hartati, Sri; Harjoko, Agus; dan Wardoyo, Rentyanto. (2006). Fuzzy Multi Attribute Decision Making (Fuzzy MADM), Graha Ilmu, Yogyakarta.

[5] Fristy Riandari, Paska Marto Hasugian, Insan Taufik (2017). Sistem Pendukung Keputusan Menggunakan Metode Topsis Dalam Memilih Kepala Departemen Pada Kantor Balai Wilayah Sungai Sumatera II Medan. Journal Of Informatic Pelita Nusantara e-ISSN 25413724 , Volume 2 No 1. 